Document downloaded from:

http://hdl.handle.net/10251/155020

This paper must be cited as:

Santos-Juanes Jordá, L.; García-Ballesteros, S.; Vercher Pérez, RF.; Amat Payá, AM.; Arqués Sanz, A. (2019). Commercial steel wool used for Zero Valent Iron and as a source of disolved iron in a combined red-ox processfor pentachlorophenol degradationm in tap water. Catalysis Today. 328:252-258. https://doi.org/10.1016/j.cattod.2019.01.007

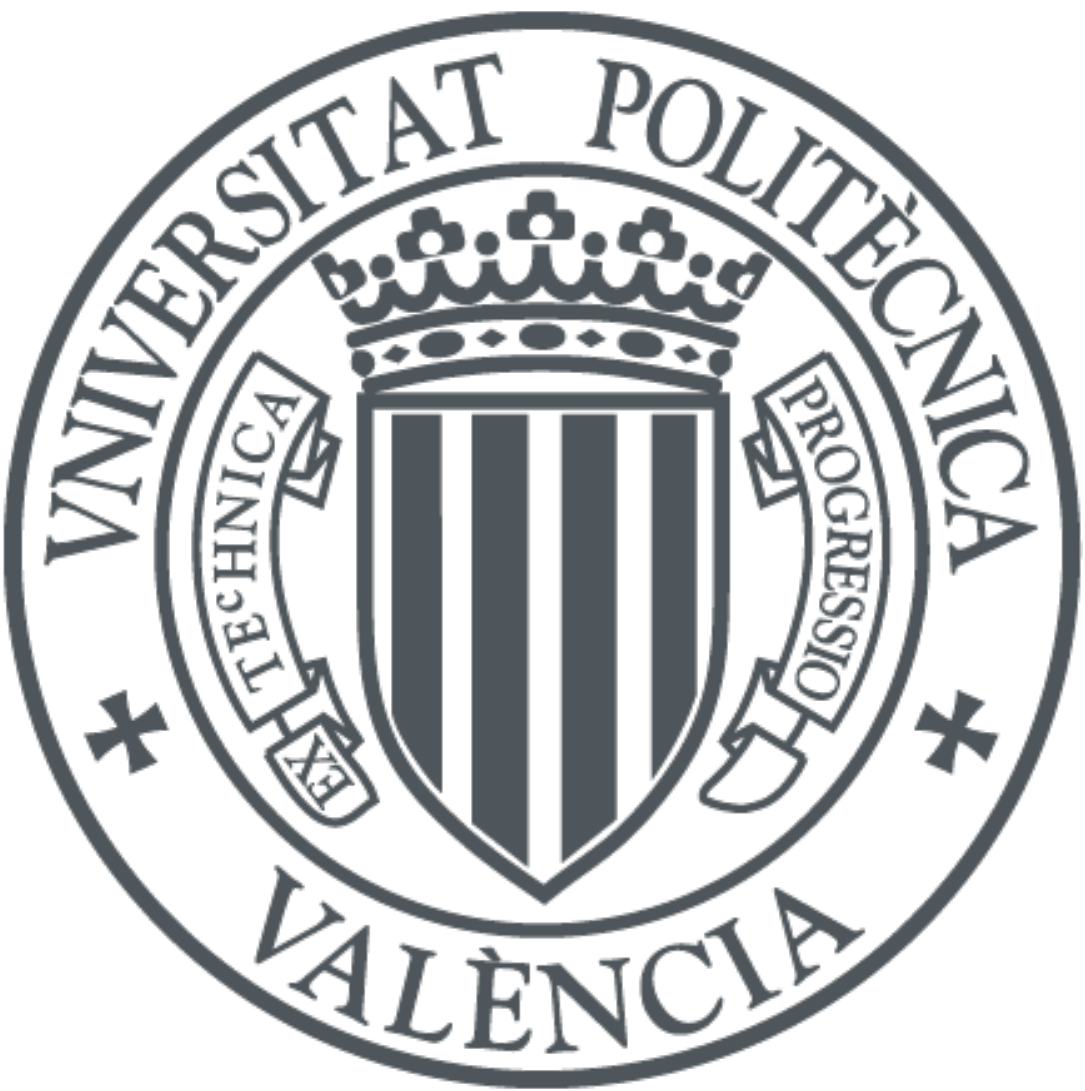

The final publication is available at

https://doi.org/10.1016/j.cattod.2019.01.007

Copyright Elsevier

Additional Information 


\section{Commercial steel wool used for Zero Valent Iron and as a \\ 2 source of dissolved iron in a combined red-ox process for 3 pentachlorophenol degradation in tap water}

5 L. Santos-Juanes*, S. García-Ballesteros, R.F. Vercher, A.M. Amat, A. Arques

6 Grupo de Procesos de Oxidación Avanzada, Departamento de Ingeniería Textil y 7 Papelera, Universitat Politècnica de València, Campus de Alcoy, Alcoy, Spain.

9 To whom correspondence should be adressed: Phone: +34966528417 . Fax: +34 966528438. E-mail: lusanju1@txp.upv.es.

\section{Abstract}

Pentachlorophenol solutions in tap water were treated with a combined process of zero valent iron (ZVI) reduction followed by a photo-Fenton oxidation. Commercial steel wool was used as ZVI source, demonstrating its effectivity for pentachlorophenol dechlorination at acidic $\mathrm{pH}$ values. The reductive pathway was monitored by the use of excitation emission matrices, showing the transformation of the initial compound into the fluorescent species 4-chlorophenol and phenol.

While the use of tap water represented a drawback in photo-Fenton oxidative reactions (at least half kinetic constants values) an improvement was achieved when the reductive stage was applied in the studied $\mathrm{pH}$ range. The transformation of pentachlorophenol into phenol produced an increase in oxidative stage rate of about 8 times. This fact could be 
23 related to the treatment time and hydrogen peroxide consumption of the photo-Fenton

24 process, enhancing the economic viability. Furthermore, the de-chlorination of the

25 pentachlorophenol minimized the possibility of releasing toxic by-products in the 26 photo-Fenton process.

27

28 Keywords: steel wool, tap water, ZVI, photo-Fenton, pentachlorophenol

29

30

\section{Graphical abstract}

31

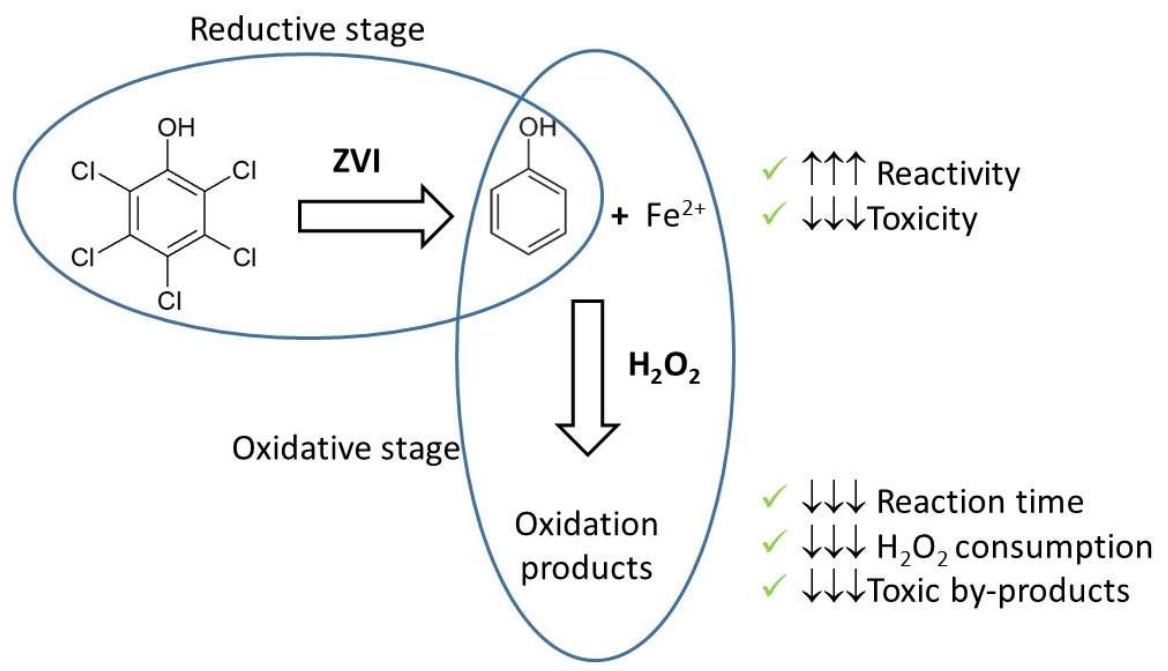

32

33 


\section{Introduction}

Advanced oxidation processes (AOPs) are a group of techniques able to produce important changes in chemical composition of pollutants, and eventually, reaching significant mineralization [1]. AOPs have been studied for the treatment of highly polluted effluents [2, 3] and recently, as a tertiary process to deal with low concentrations of recalcitrant pollutants [4,5]. In both cases, the presence of salts has been described as detrimental, because their scavenging effect on the reactive species involved in the AOP results in an important decrease in reaction rates [6]. This negative effect can be overcome by working under stronger oxidation conditions, but this strategy should be disregarded for economic and ecologic reasons, at least when dealing with pollutants at low concentration [4]; in addition, when pollutant/inorganic salts ratio decreases, the reactive species is more likely to find the inorganic ion than the pollutant, thus increasing its scavenging role. For these reasons, the option of coupling a pre-reductive stage seems attractive, especially for those compounds with electronwithdrawing groups (e.g. nitro groups, sulfonates, cyano group) that deactivate electrophilic attack of the reactive species [7]. In this case, the negative effect produced by the presence of salts can be overcome if the pre-reductive stage forms more reactive intermediates vs. oxidative processes.

Zero valent iron (ZVI) can act as reducing agent (standard redox potential of $-0.44 \mathrm{~V}$ ) in the pre-reductive stage; in fact ZVI-based processes are commonly employed for decontamination of water and groundwater [8]. In particular, ZVI has been used to remove different types of pollutants from water such as chlorinated compounds, arsenic, nitrate, dyes or nitro-aromatic compounds [9-11]. It is important to mention that the 
58 presence of dissolved salts enhances ZVI reduction process, since they promote the 59 oxidation of the iron [12].

60 When ZVI is present in water a large number of reactions can occur, but the following 61 ones play the major role in most cases [13]:

$62 \mathrm{Fe}^{0}+2 \mathrm{H}^{+} \rightarrow \mathrm{Fe}^{2+}+\mathrm{H}_{2} \uparrow$

$632 \mathrm{Fe}^{0}+\mathrm{O}_{2}+\mathrm{H}_{2} \mathrm{O} \rightarrow 2 \mathrm{Fe}^{2+}+4 \mathrm{OH}^{-}$

64 According to the reactions above, ferrous salts are released into the solution during the

65 ZVI process. As iron cations are present in solution, Fenton and related processes can 66 be used in the oxidative stage, in particular if hydrogen peroxide is added to the reaction 67 mixture [14].

Fenton process consists in a combination of ferrous salts and hydrogen peroxide at an optimum $\mathrm{pH}$ of 2.8 , that are able to generate highly reactive species, mainly hydroxyl radicals. Fenton can be accelerated by light (photo-Fenton) and interestingly, sunlight can be used for this purpose [15]. The ability of this process to oxidize a wide range of pollutants under different experimental conditions is well-established [16] and hence, increasing attention has been paid to several aspects related to (photo)-Fenton, such as economics, automatization or modelling [17-19].

The application of Fenton-related processes as tertiary treatment suggests the use of mild conditions (near neutral $\mathrm{pH}$ and low iron and hydrogen peroxide concentrations [20]). In this context, a pre-reductive stage can facilitate photo-Fenton oxidation and, in addition to this, corrosion of zero-valent iron (ZVI) could be used as a continuous source of iron salts replacing the amount that could suffer inactivation via formation of iron oxides or hydroxides [21]. 
81 Separation of the reductive and oxidative stages in different parts of the reactor allow tuning the best conditions for each stage. In particular, this type of set-ups avoids the unnecessary consumption of hydrogen peroxide by reaction with ZVI permits irradiation without light scattering [10]. From an economical and practical point of view, commercial ZVI with high specific surface area (e.g. steel wool) seems a good choice for this purpose. Furthermore, possible negative effects related to nano-iron particles in the environment are also excluded [22].

This combined redox process would be meaningful for some applications, such as treatment of effluents containing pollutants reluctant to chemical oxidation and/or with potential to generate non-desired oxidation by-products; putting all together ZVI/photoFenton could be a niche application for pollutants difficult to oxidize, present at low concentration, with high amounts of salts in the effluent, when mild oxidizing conditions are required and the release of toxic oxidation by-products cannot be disregarded.

With this background, the aim of this work is to study a combined ZVI-Fenton process using tap water. Commercial steel wool has been used as an iron source and a reaction set-up able to separate ZVI-based reduction and photo-Fenton has been employed. As factors influencing the photo-Fenton process are well-known, special emphasis will be paid to the reductive phase. A typical halogenated toxic compound, pentachlorophenol (PCP), has been used as a model pollutant. This compound is widely employed as a pesticide, it is one of the chlorinated compounds less reactive towards oxidative processes [23] and problems associated to its incomplete oxidation have been reported [24]. 


\section{Experimental}

105

106

107

108

109

110

111

112

113

114

115

116

117

118

119

120

121

122

123

124

125

126

127 128

\subsection{Reagents.}

High purity PCP, 2,4-dichlorophenol (2,4-DCP), 4-chlorophenol (4-CP) and phenol were supplied by Sigma-Aldrich. Sulphuric acid (96\%), sodium hydroxide (99\%) ferrous sulphate (99\%), hydrogen peroxide (30\%) and acetonitrile (HPLC grade) were provided by Panreac. The water employed was tap water from Alcoy (Spain) water supply (table 1). The commercial steel wool (iron with $0.1 \%$ of carbon) classified as fine grade with a fiber thickness of ca. $0.05 \mathrm{~mm}$ was employed as Zero Valent Iron (ZVI). This commercial product is available in long reels of $8 \mathrm{~cm}$ width and $0.5 \mathrm{~cm}$ thickness.

\subsection{Experimental set up}

The target solution in reductive processes was pentachlorophenol $(1 \mathrm{mg} / \mathrm{L})$ in tap and Mili-Q water. In photo-Fenton, in addition to PCP, 2,4-DCP, 4-CP and phenol were also used as substrates (always with an initial concentration of $1 \mathrm{mg} / \mathrm{L}$ ). This range of concentrations was chosen in order to allow a reliable monitoring of the kinetics of the process and to assess the effect of operational variables. Furthermore, $1 \mathrm{mg} / \mathrm{L}$ is not far from the total amount of emerging pollutants that can be found in the effluents of wastewater treatment plants [4].

The commercial steel wool (1.4 g) was placed into a cylindrical container of $17 \mathrm{~mm}$ diameter and $220 \mathrm{~mm}$ height located over an open glass reactor with magnetic stirring (Scheme 1). The solution was continuously recirculated from the open reactor to the steel wool at a flow rate of $20 \mathrm{~mL} / \mathrm{min}$ using a peristaltic pump PR7 (SEKO). The solution was flown through the steel wool by gravity and returned to the open reactor. 
129 A pH-meter was placed inside the reactor. Periodically, samples were taken for monitoring the pollutant and dissolved iron concentration.

131 For photo-Fenton reactions, a solar simulator (Oriel Instruments, Model 81160 equipped with a $300 \mathrm{~W}$ xenon lamp) whose emission spectrum closely matches the solar one was employed to irradiate the open glass reactor. The apparatus was equipped with specific glass filters for cutting off the transmission of wavelengths below $300 \mathrm{~nm}$ was used. The UVA irradiance $(320-400 \mathrm{~nm})$ was $32 \mathrm{~W} / \mathrm{m}^{2}$. This value represents an average irradiance in a sunny country and it has been used as a reference, by many authors, to normalize reaction time supposing a constant sun irradiance $\left(\mathrm{t}_{30 \mathrm{w}}\right)$ [16]. For each experiment, the reactor was loaded with $250 \mathrm{~mL}$ of solution and the $\mathrm{pH}$ was adjusted to the desired value by dropwise addition of sulphuric acid or sodium hydroxide; in some experiments only initial $\mathrm{pH}$ was adjusted, while in other cases, a constant $\mathrm{pH}$ was kept along the process. For photo-Fenton reactions, hydrogen peroxide was added to reach a concentration of $2.5 \mathrm{mg} / \mathrm{L}$; this accounts for ca. twice the stoichiometric amount required to completely oxidize PCP and it was chosen to minimize the scavenging role of the excess of $\mathrm{H}_{2} \mathrm{O}_{2}$ towards photo-Fenton (17). Iron employed in the oxidative reaction was $5 \mathrm{mg} / \mathrm{L}$, that was in the range of the amount of iron released by $\mathrm{ZVI}$ at $\mathrm{pH}=5$; furthermore, it has been demonstrated that this is a convenient concentration to drive mild photo-Fenton [4]. Samples were periodically collected from the reactor and filtered through $0.45 \mu \mathrm{m}$ nylon filters (Millipore Millex$\mathrm{HN}$ ) before analyses. Eventually, in order to prevent the decomposition of organic components after sampling, samples were immediately diluted $(1: 3 \mathrm{v} / \mathrm{v})$ with methanol. All experiments have been repeated at least twice. 


\subsection{Chemical analysis}

155 Pentachlorophenol and its reductive products concentration were determined by high 156 performance liquid chromatography. The apparatus employed was a LaChrom from 157 Merck-Hitachi equipped with autosampler and diode array detector. A reverse phase 158 column LiChrospher® $100 \mathrm{RP}-18(5 \mu \mathrm{m})$ was used and a mixture of $1 \mathrm{mM}$ sulfuric acid and acetonitrile $(20 / 80 \%)$ were employed as a mobile phase in a flow rate of 1.0 $\mathrm{mL} / \mathrm{min}$.

161 The fluorescence Excitation Emission Matrices (EEMs) were recorded with a modular

162 QuantaMaster spectrofluorometer and collected by subsequent scanning emission from 163300 to $600 \mathrm{~nm}$ at $5 \mathrm{~nm}$ increments by varying the excitation wavelength from 250 to $164550 \mathrm{~nm}$ at $5 \mathrm{~nm}$ increments. Data at lower excitation wavelengths were not recorded because of the excessive background noise, caused by the low intensity of the lamp in the range of 200-250 $\mathrm{nm}$. The spectra were recorded using excitation and emission slit

167 bandwidths of $5 \mathrm{~nm}$. The fluorescence intensities are reported in c.p.s. (counts per 168 second).

169 UV-Vis absorption spectra were recorded on a Helios $\gamma$ spectrophotometer (Thermo 170 Scientific), using quartz cells of $1.0 \mathrm{~cm}$ optical path length.

171 The concentration of iron species in the water was measured according to the o172 phenanthroline standardized spectrometric procedure (ISO 6332) [25]. Hydrogen 173 peroxide presence and consumption was checked by the use of colorimetric strips 174 (MQuant Peroxide Test). 


\section{Results and discussion}

177

178

179

180

181

182

183

184

185

186

187

188

189

190

191

192

193

194

195

196

197

198

199

200

\subsection{Effect of $\mathrm{pH}$ in pentachlorophenol reductive degradation}

A first set of experiments was carried in tap water at different initial $\mathrm{pH}$ values in order to study the effect of this parameter on the reduction of PCP by ZVI. The $\mathrm{pH}$ was adjusted before the reaction to 3,5 and 7 . Pollutant concentration, dissolved iron (released by ZVI) and $\mathrm{pH}$ were monitored along the process and results are shown in Figure 1. At $\mathrm{pH} 7$, no significant decrease in PCP concentration was observed, at $\mathrm{pH}=5$ some degradation of PCP was observed (20\% removal after $90 \mathrm{~min})$ and at $\mathrm{pH}=3$, higher removal was reached (50\% after 1 hour), but again in this case, a decrease in the reaction rate was observed beyond this point. The amount of iron released into the solution followed a similar trend: it was very low at $\mathrm{pH}=7$ and increased with decreasing $\mathrm{pH}$ values; in some cases, a decrease in dissolved iron was observed (e.g. at $\mathrm{pH}=5$ ) that can be attributed to the iron (III) precipitation. The $\mathrm{pH}$ variation is different in all cases: while at initial $\mathrm{pH}=7$, variation is lower than a unit, reaching values close to 8 , followed by a slight decrease at the end of the process; similar behavior is observed for the experiment with initial $\mathrm{pH}=5$, where an increase of less than $2 \mathrm{pH}$ unit was observed (never reaching $\mathrm{pH}=7$ ), again followed by a slight decrease. In the case of $\mathrm{pH}=3$, the $\mathrm{pH}$ increase was higher at the beginning of the reaction (ca. 3.5 units, to reach values around 6.5) and then remained constant.

These results seem to indicate that PCP removal is favored by acidic $\mathrm{pH}$ and it is stopped once solution approaches neutral values, iron release also occurs faster at acidic medium and the decrease observed at the end of the process, might be due to the precipitation of iron hydroxides; the $\mathrm{pH}$ increase might be related to $\mathrm{H}^{+}$reduction to form $\mathrm{H}_{2}$ and the final slight decrease can be due to the precipitation of iron hydroxide. 
201 Finally, it seems that all three processes are closely related: ZVI oxidation requires $\mathrm{H}^{+}$

202

203

204

205

206

207

208

209

210

211

212

213

214

215

216

217

218

219

220

221

222

223

224

225 reduction and PCP removal is coupled with these processes: this is in agreement with $\mathrm{H}_{2}$ acting as reducing agent for PCP, although other processes should not be ruled out, because of the complexity of the system. Also interestingly, the amount of iron released in the solution (above $5 \mathrm{mg} / \mathrm{L}$ ) is in the range of the concentrations employed for photoFenton, what might favor coupling of ZVI and photo-Fenton processes without further iron addition.

To gain further insight into de effect of $\mathrm{pH}$, three experiments were carried out maintaining the $\mathrm{pH}$ constant during all reaction time by small additions of sulfuric acid at the values of 3,4 and 5. Interestingly, keeping constant the $\mathrm{pH}$ value allowed obtaining important degradation percentages, which were not stopped (Figure 2). Best results were obtained at the most acidic value, 3 , with more than $90 \%$ removal in two hours of reaction. At this $\mathrm{pH}$, the iron released into the solution was more than $40 \mathrm{mg} / \mathrm{L}$. When the $\mathrm{pH}$ was maintained at 4 , the reaction was only slightly slower and the amount of iron in solution also decreased to $20 \mathrm{mg} / \mathrm{L}$. Finally, when the reaction was carried out at $\mathrm{pH}=5$, the final degradation was ca. $85 \%$ and the dissolved iron reached a maximum of $12 \mathrm{mg} / \mathrm{L}$ and then slightly decreased, most probably because of precipitation at this $\mathrm{pH}$. However, the amount of iron dissolved in the solution was high enough to perform a photo-Fenton process. Putting all this together, although best results were reached at $\mathrm{pH}=3$, the process can be extended up to $\mathrm{pH}=5$. A key parameter for the good performance of this approach is the high iron/pollutant ratio that can be applied, as ZVI is immobilized as a wool. 


\subsection{Mechanistic studies using excitation-emission matrices}

227 Once the degradation of PCP was achieved and the $\mathrm{pH}$ working range assessed, a series of experiments were planned in order to elucidate the mechanism involved in PCP removal, as PCP decrease can be due to different processes. For this reason, it is important to demonstrate that a reductive reaction of de-halogenation was predominating.

The mechanistic route for PCP de-halogenation have been described in depth for several systems [26, 27]. It involves the consecutive chlorine removal from PCP to produce phenol through the formation of tetrachlorophenol, trichlorophenol, dichlorophenol and chlorophenol. In some cases, the formation of chlorine anion has been employed for monitoring the de-chlorination of organic compounds. In our case, the use of tap water with important amounts of chlorine $(27 \mathrm{mg} / \mathrm{L})$, the initial low concentration of pentachlorophenol $(1 \mathrm{mg} / \mathrm{L})$ and the low expected concentration of by-products made the use of excitation emission matrices (EEMs) an adequate choice, as it has been demonstrated as a good technique to detect major trends in the composition of organic matter through a treatment [28]. With this objective in mind, EEMs were recorded for PCP, 2,4-DCP, 4-CP and phenol solutions in tap water. As presented in figure 3, PCP and 2,4-DCP showed no fluorescence, while 4-CP showed an important emission spectrum in the zone of 300 to $340 \mathrm{~nm}$ when excited in the 250 to $290 \mathrm{~nm}$ domain. Finally, the phenol solution presented a strong emission in the range of 300 to 340 when excited between 250 to $330 \mathrm{~nm}$ and 500 to $550 \mathrm{~nm}$.

247 Once the reference compounds were recorded, the EEM of samples taken at different degradation levels were also measured (Figure 4). The initial sample showed no significant emission, as expected for PCP. As PCP removal occurred, signals appeared with emission between 300 to $340 \mathrm{~nm}$ when excited between 250 to $350 \mathrm{~nm}$, which can 
251 be attributed to phenol formation. Nevertheless the presence of the other fluorescent

252

253

254

255

256

257

258

259

260

261

262

263

264

265

266

267

268

269

270

271

272

273

274

275 compound, 4-CP cannot be completely discarded, since emitting and exciting zones are partially overlapped with phenol. Finally, EEM obtained when PCP was submitted to photo-Fenton showed no significant emission. Thus, EEM is an important piece of evidence to support PCP reduction to phenol.

\subsection{The role of salts in reductive/oxidative treatment}

The presence of salts in tap water have been reported as favourable for iron corrosion and consequently for reductive reactions when applying ZVI $[10,12]$. Contrary to this, the scavenging effect of dissolved salts results in a decrease of the oxidation kinetics [29]. In order to determine the extent of this effect in our system, reduction of PCP was carried out in Mili-Q water to compare with the results obtained in section 3.1 with tap water. Again this case, $\mathrm{pH}$ was kept constant at values of 3, 4 and 5.

Figure 5a shows the pseudo-first order kinetic constant for PCP removal in tap and Mili-Q water at the different working $\mathrm{pH}$. In all cases, kinetic constants were higher when the reaction was driven in tap water confirming the positive role of the presence of salts. Nevertheless important PCP reduction was also observed in Milli Q water; this could be partly attributed to the addition of electrolytes (e.g. sulphuric acid) to modify the $\mathrm{pH}$ values. In fact, differences between both aqueous matrixes were less relevant at $\mathrm{pH}=3$, where more sulphuric acid was present. The final amount of dissolved iron was also monitored (Figure 5b), and in line with the previous results higher amounts of iron were released in tap water.

In order to check the effect of salts on the oxidative stage, a series of experiments were dedicated to study the photo-Fenton oxidation of PCP, 2,4-DCP, 4-CP and phenol. The degradation of each pollutant was studied in separate experiments $(1 \mathrm{mg} / \mathrm{L})$, and the 
series were run with Mili-Q and tap water (Figure 6) at the three studied $\mathrm{pH}$ values. As indicated in the introduction, the presence of electron withdrawing groups results in a more reluctant behaviour towards oxidation. In fact, the following order of reactivity was found: phenol $>4-\mathrm{CP}>2,4-\mathrm{DCP}>\mathrm{PCP}$. This proves that de-chlorination in the reductive stage of PCP to form phenol is meaningful in view of applying photo-Fenton. Regarding $\mathrm{pH}$, the expected behaviour was found, being the reaction systematically faster at $\mathrm{pH}=3$; although at $\mathrm{pH}=5$ reaction was clearly slower, significant removal was observed, indicating that application of photo-Fenton at this medium should not be ruled out when dealing with pollutants at low concentration. Finally, the scavenging role of salts was clear in this case, as rate constants were lower in the experiments with tap water, being this effect more significant at $\mathrm{pH}=5$, most probably due to the lower availability of reactive species. This makes more interesting the ZVI/photo-Fenton coupling, as the oxidation of phenol in tap water is faster than of PCP even when this pollutant is dissolved in Milli-Q water.

\subsection{Environmental considerations}

The presence of chlorinated compounds in water have deserved the attention from researchers during the last 30 years due to its high toxicity. The T.E.S.T software (Toxicity Estimation Software Tool) developed by the Environmental Protection Agency (EPA) reports the following values of toxicity for all the chlorinated phenols expressed as Daphnia magna LC50 (48 h) mg/L: PCP (0.73); 2,3,5,6-TetraCP (0.57); 2,4,6-TCP (6.32); 2,4-DCP (2.6); 4-CP (4.82). Finally, the toxicity of phenol expressed as Daphnia magna LC50 (48 h) $\mathrm{mg} / \mathrm{L}$ is 13.29 . Therefore, the reduction of PCP to phenol decreases the toxicity in ca. 20 times. This fact, together with the increase of reactivity towards oxidation in 8 times, should be enough to justify a cheap pre- 
301 reductive stage before the photo-Fenton process. But in addition to this, the direct oxidation without pre-treatment has been described as dangerous if complete oxidation cannot be achieved, as some toxic condensation products have been identified $[24,30]$.

304 Finally, the use of steel wool as ZVI has also an environmental benefit since problems 305 associated to the toxicity of nano-ZVI have been also published [22] 


\section{Conclusions}

309 A procedure combining reductive and oxidative stages demonstrated to be meaningful 310 for the treatment of PCP, a toxic and low reactive compound against oxidation with

311 photo-Fenton. This combined process seems to be convenient in systems in which the 312 oxidative treatment (photo-Fenton) is not favored, namely compounds difficult to 313 oxidize, present at low concentration, with high amounts of salts in the effluent, when 314 mild oxidizing conditions are required and/or when the release of toxic oxidation by315 products cannot be disregarded.

316 Although the reduction was faster at $\mathrm{pH}=3$, it could be extended until $\mathrm{pH}=5$ with no 317 significant loss of efficiency and the presence of salts (e.g tap water) did not represent a 318 drawback for the ZVI process. The major product formed in the process, namely phenol, 319 is more easily oxidized via photo-Fenton than PCP and the iron released during the 320 reduction can be employed in the oxidative step.

321 The use of commercial steel wool as reducing agent can improve the economic feasibility of the process making this alternative reductive-oxidative treatment interesting, as it allows designing the experimental set-ups that separate the oxidative and reductive stages. In fact, a possibility to be studied in future work is the application of the alternative reductive and oxidative stages in short reaction times by adding controlled amounts of hydrogen peroxide.

327 Finally, EEM has been confirmed as a good alternative to more sophisticated 328 chromatographic methods. When fine analysis of the complex mixture is not required, 329 the use of EEM allows following major trends in organic matter composition. 
332 Authors want to acknowledge the financial support of Spanish Ministerio de Economía 333 y Competitividad (CTQ2015-69832-C4-4-R), European Union (645551-RISE-2014, 334 MAT4TREAT).

335

336 
338 [1] V. Augugliaro, M. Litter, L. Palmisano, J. Soria. J. Photoch. Photobio. C 7 (2006) $339 \quad 127-144$.

340 [2] A. Zapata, I. Oller, L. Rizzo, S. Hilgert, M.I. Maldonado, J.A. Sánchez-Pérez, S. 341 Malato. Catal. Today 144 (2009) 94-99.

342 [3] F. Torrades, M. Pérez, H.D. Mansilla, J. Peral. Chemosphere 53 (2003) 1211-1220.

343 [4] N. Klamerth, S. Malato, A. Agüera, A. Fernández-Alba. Water Res. 47 (2013) 833344840.

345 [5] A. Bernabeu, R.F. Vercher, L. Santos-Juanes, P.J. Simón, C. Lardín, M.A. Martínez, 346 J.A. Vicente, R. González, C. Llosá, A. Arques, A.M. Amat. Catal. Today 61 (2011) $347 \quad 235-240$.

[6] J. Kiwi, A. Lopez, V. Nadtochenko. Environ. Sci. Technol. 34 (2000) 2162-2168.

349 [7] D. Juretic, H. Kusic, N. Koprivanac, A. Loncaric Bozic. Water Res. 46 (2012) 3074$350 \quad 3084$.

351 [8] F. Fu, D. D. Dionysiou, H. Liu. J. Hazard. Mater. 267 (2014) 194-205.

352 [9] J.A. Donadelli, L. Carlos, A. Arques, F.S. García Einschlag. Appl. Catal. B: 353 Environ. 231 (2018) 51-61.

354 [10] L. Santos-Juanes, F.S. García Einschlag, A.M. Amat, A. Arques. Chem. Eng. J. $355310(2017) 484-490$.

356 [11] J. M. Calo, L. Madhavan, J. Kirchner, E.J. Bain. Chem. Eng. J. 189- 190 (2012) $357 \quad 237-243$. 

224-248.

361

[14] G.B. Ortiz de la Plata, O. M. Alfano, A. E. Cassano. J. Photochem. Photobiol. A: 362 Chem. 233 (2012) 53-59

363

[15] J.J. Pignatello, E. Oliveros, A. MacKay. Crit. Rev. Environ. Sci. Technol. 36 364 (2006) $1-84$.

365

[16] S. Malato, P. Fernández-Ibáñez, M.I. Maldonado, J. Blanco, W. Gernjiak, Catal. 366 Today 147 (2009) 1-59.

367

[17] E. Ortega-Gómez, E. Moreno Úbeda, J. D. Álvarez Hervás, J. L. Casas López, L. 368 Santos-Juanes, J. A. Sánchez Pérez. J. Hazard. Mater. 237-238 (2012) 223-230.

[18] L. Santos-Juanes Jordá, M.M. Ballesteros Martín, E. Ortega Gómez, A. 370 Cabrera Reina, I.M. Román Sánchez, J.L. Casas López, J.A. Sánchez Pérez. J. Hazard. 371 Mater. 186 (2011) 1924-1929.

372

[19] A. Cabrera Reina, L. Santos-Juanes, J.L. García Sánchez, J.L. Casas López, M.I. 373 Maldonado Rubio, G. Li Puma, J.A. Sánchez Pérez. Appl. Catal. B: Environ. 166 374 (2015) 295-301.

375 [20] J. Gomis, L. Carlos, A. Bianco Prevot, A.C.S.C. Teixeira, M. Mora, A.M. Amat, R. 376 Vicente, A. Arques. Catal. Today 240 (2015) 39-45.

377 [21] I. Carra, S. Malato, M. Jiménez, M.I. Maldonado, J.A. Sánchez Pérez. Chem. Eng. 378 J. 235 (2014) 132-140. 
379 [22] Y. Xie, H. Dong, G. Zeng, L. Tang, Z. Jianga, C. Zhang, J. Deng, L. Zhang, Y. 380 Zhanga. J. Hazard. Mater. 321 (2017) 390-407.

381 [23] M. Pera-Titus, V. Garcia-Molina, M.A. Baños, J. Giménez, S. Esplugas. Appl. 382 Catal. B: Environ. 47 (2004) 219-256

383 [24] M. Muñoz, Z.M. de Pedro, J.A. Casas, J.J. Rodriguez. J. Hazard. Mater. 190 (2011) $384993-1000$.

385 [25] Standard Methods Online -- Standard Methods for the Examination of Water and 386 Wastewater. http://standardmethods.org/

387 [26] L. Yin, J. Niu, Z. Shen, J. Chen. Environ. Sci. Technol. 44 (2010) 5581-5586.

388 [27] Y. Kim, E.R. Carraway. Environ. Sci. Technol. 34 (2000) 2014-2017.

389 [28] S. García-Ballesteros, M. Mora; R. Vicente; C. Sabater; M.A. Castillo; A. Arques 390 Sanz; A.M. Amat Payá. Chem Eng. J. 288 (2016) 126-136.

391 [29] J. Soler, A. García-Ripoll, N. Hayek, P. Miró, R. Vicente, A. Arques, A.M. Amat. 392 Water Res. 43 (2009) 4441-4450.

393 [30] W. Pan, D. Zhang, Z. Han, J. Zhan, C. Liu. Environ. Sci. Technol. 47 (2013) 84893948498.

395

396

397 


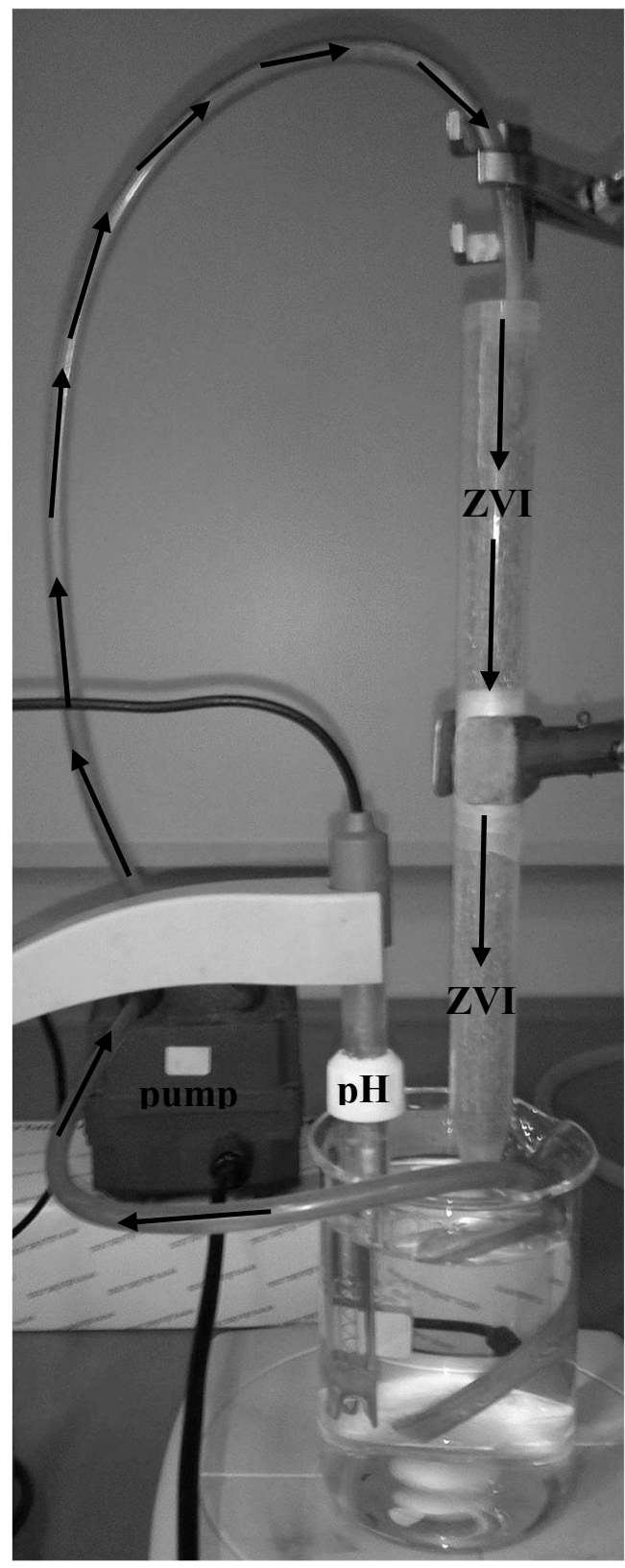

Scheme 1: Experimental set up employed in the reductive process 
A

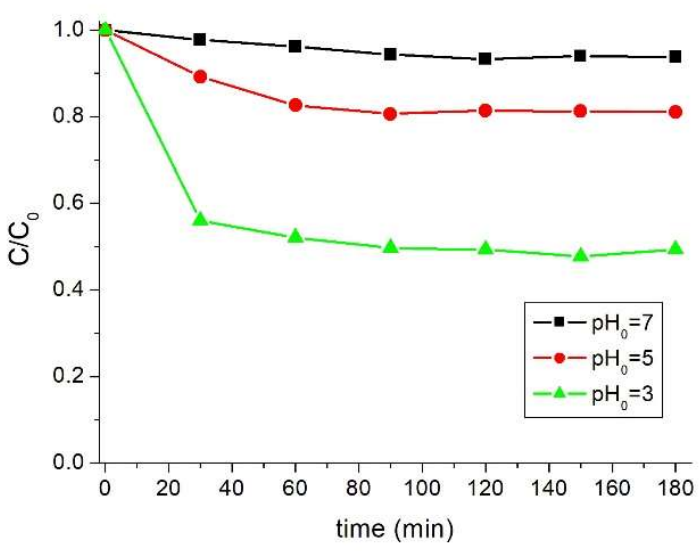

401

B

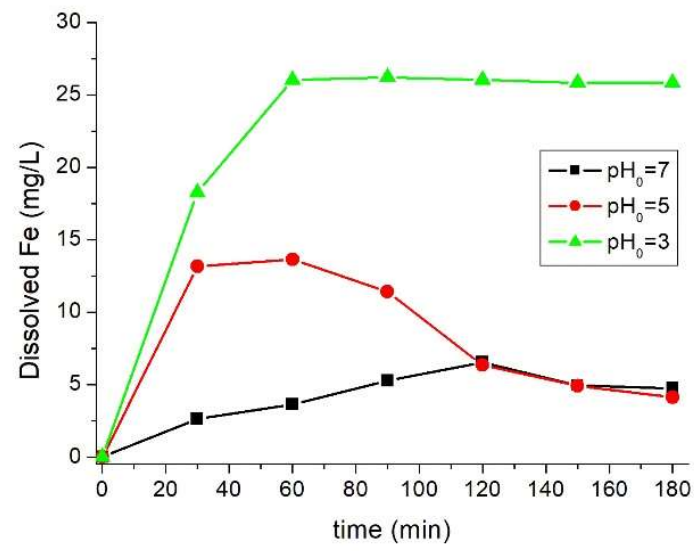

402

C

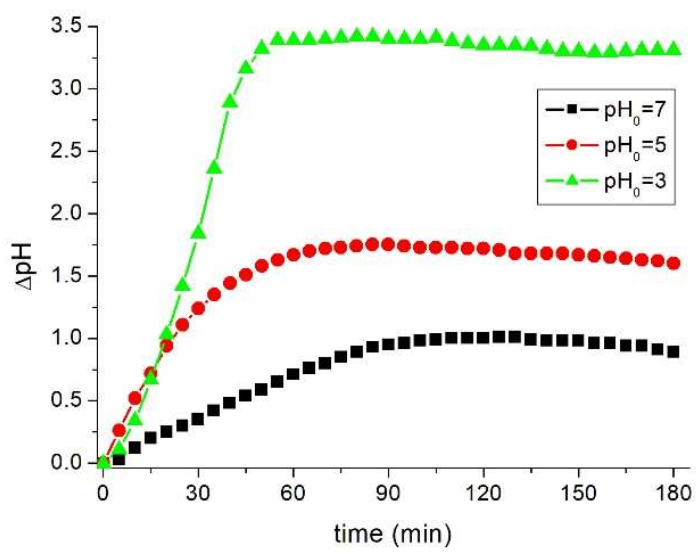

403

404 Figure 1: PCP $(1 \mathrm{mg} / \mathrm{L})$ removal by ZVI under different $\mathrm{pH}$ conditions: Variation of 405 some parameters vs time: relative concentration (A), dissolved iron (B) and $\mathrm{pH}(\mathrm{C})$. 
A

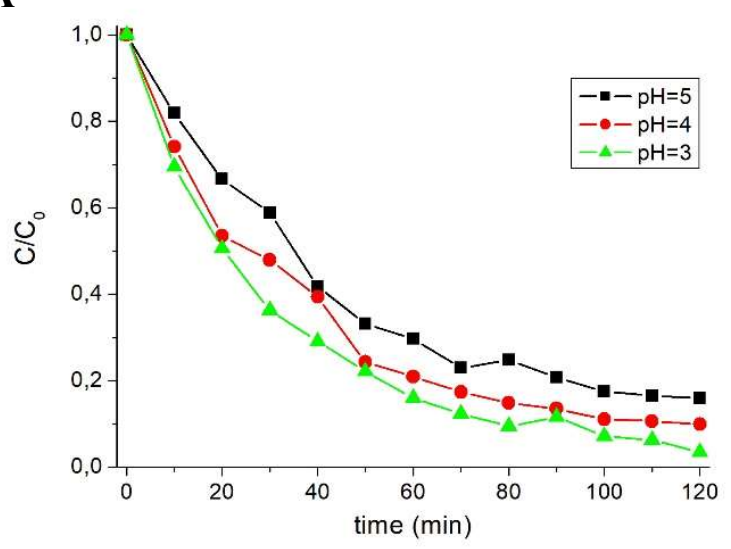

407

B

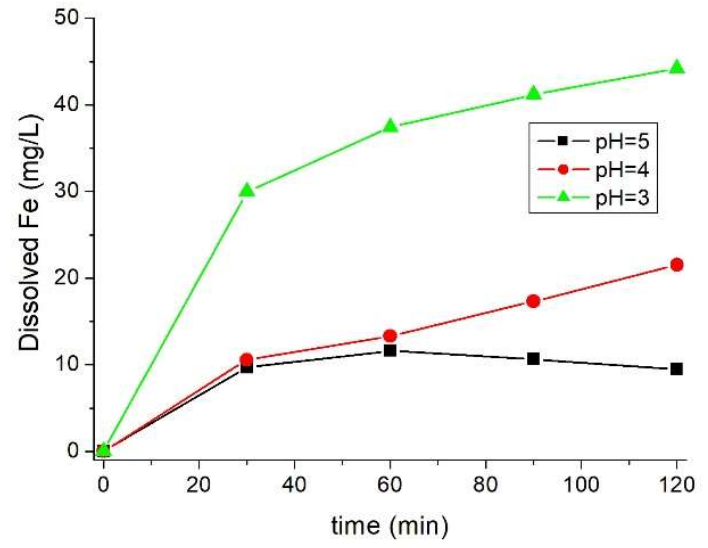

408

C

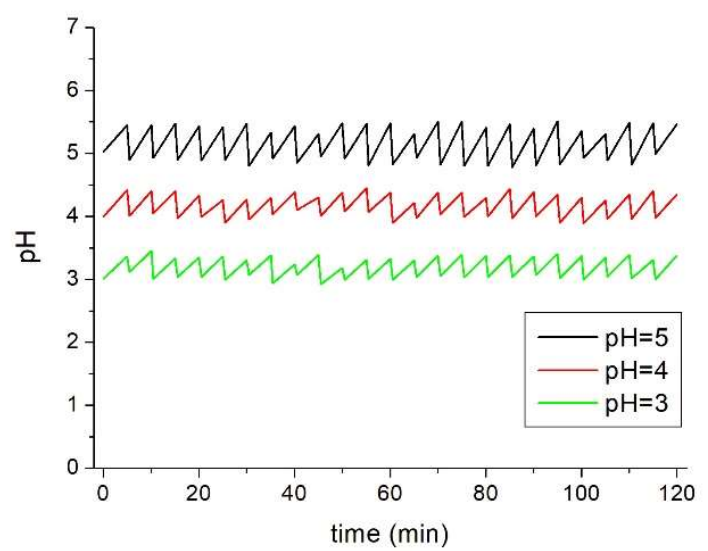

409

410 Figure 2: Evolution of pollutant removal (A), dissolved iron (B) and $\mathrm{pH}$ oscillation (C)

411 for reductive experiments carried out at different $\mathrm{pH}$ values.

412 

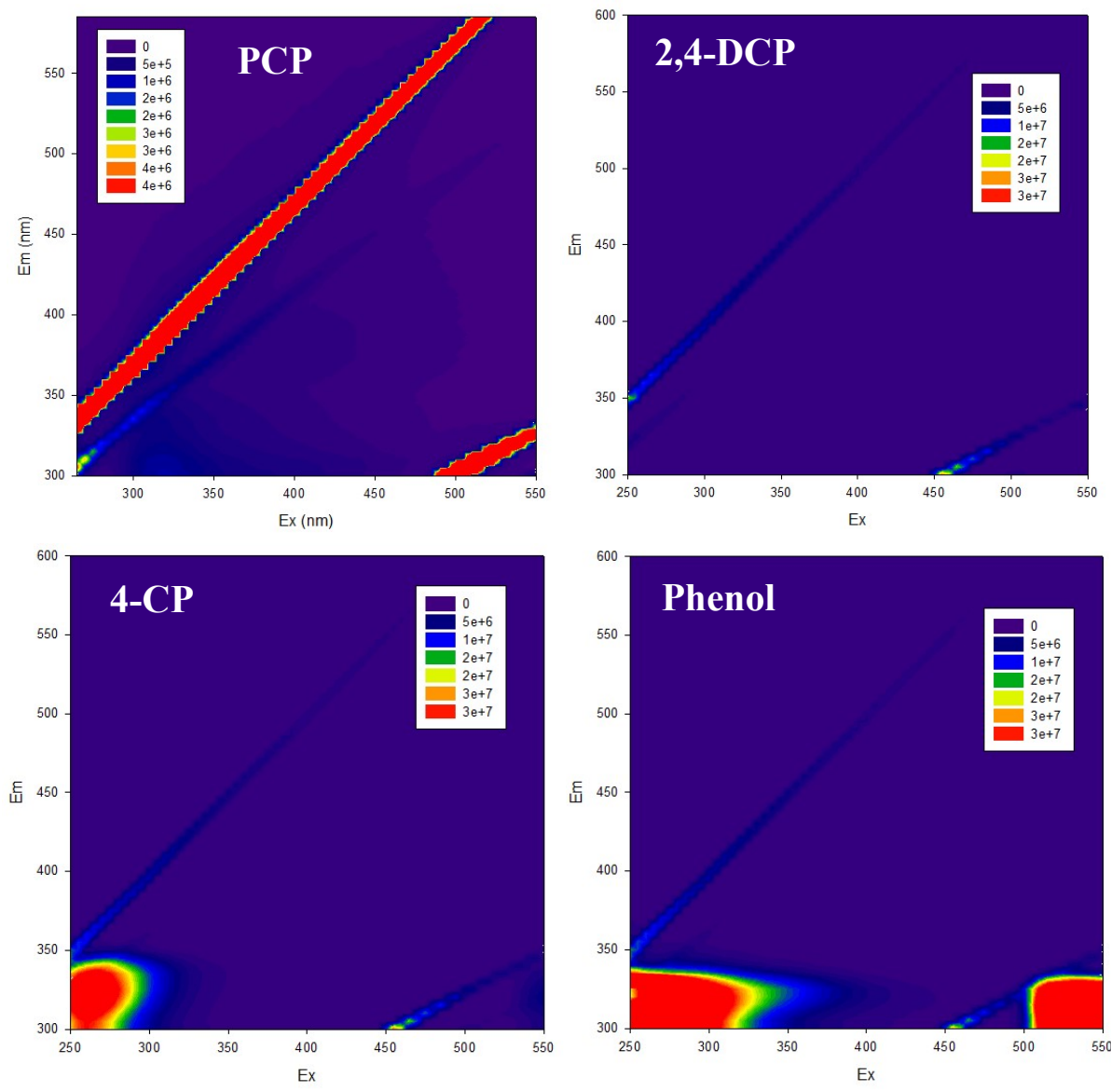

414

Figure 3: Excitation emission matrices of Pentachlorophenol (PCP); 2,4-Dichlorophenol

(2,4-DCP); 4-Chlorophenol (4-CP) and Phenol (From left to right, top to bottom).

417 

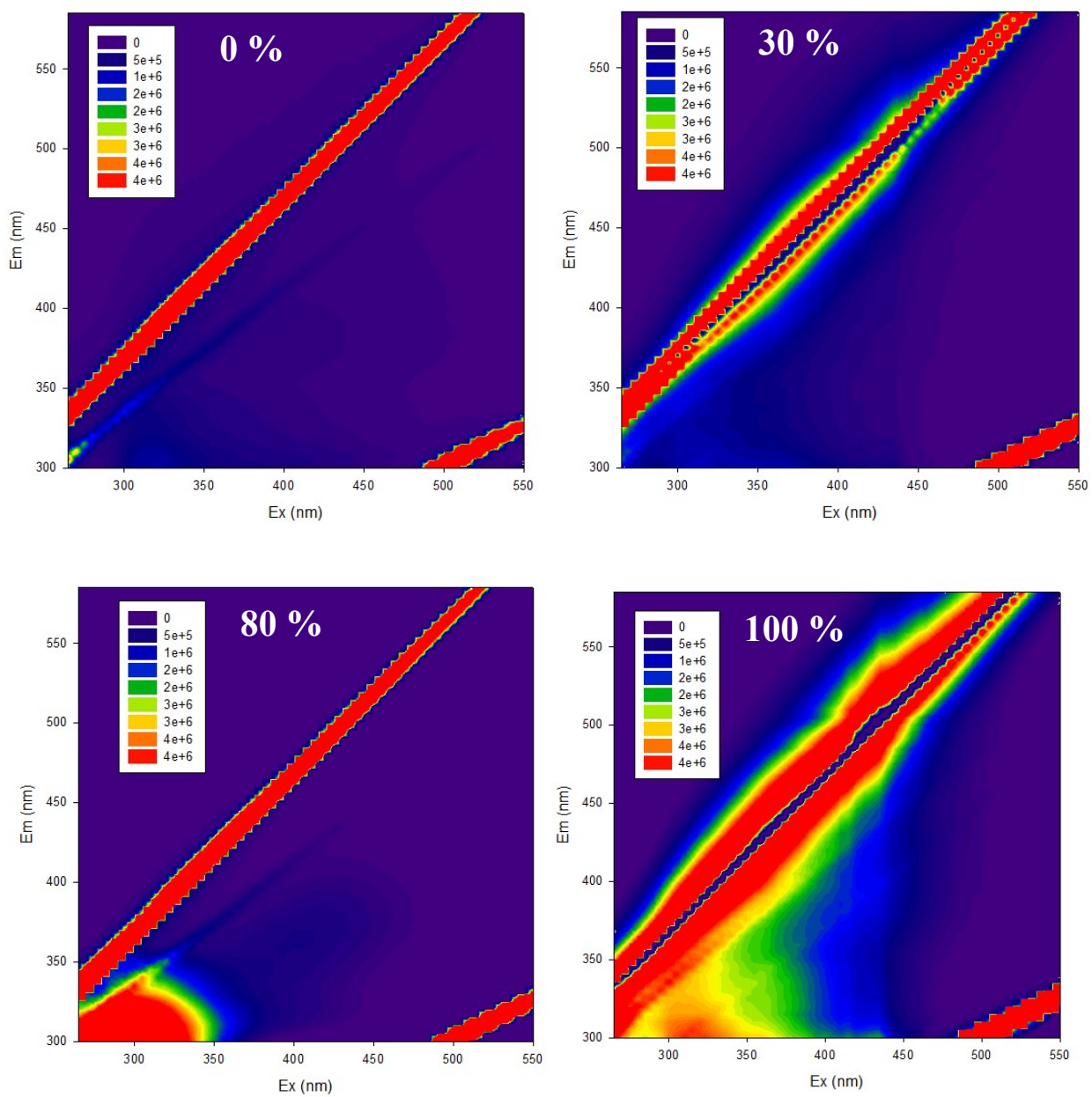

Figure 4: Excitation emission matrices of Pentachlorophenol (PCP) at different

421 percentages of removal: $0,30,80$ and $100 \%$ (From left to right, top to bottom).

422 


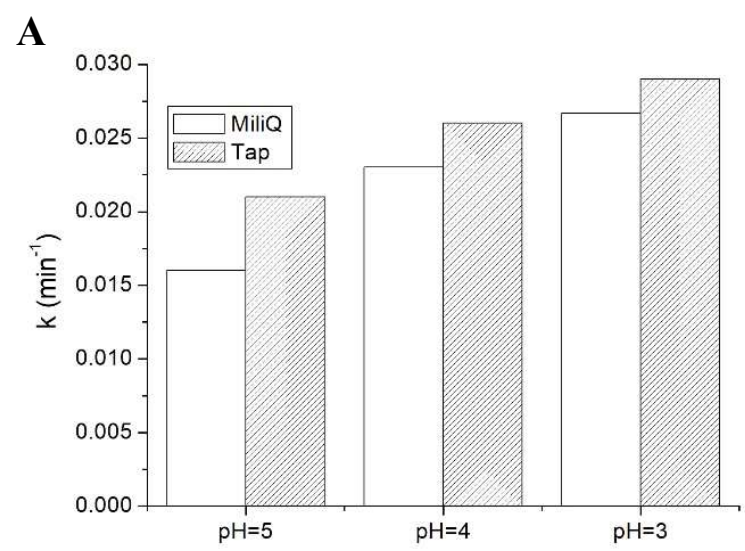

423

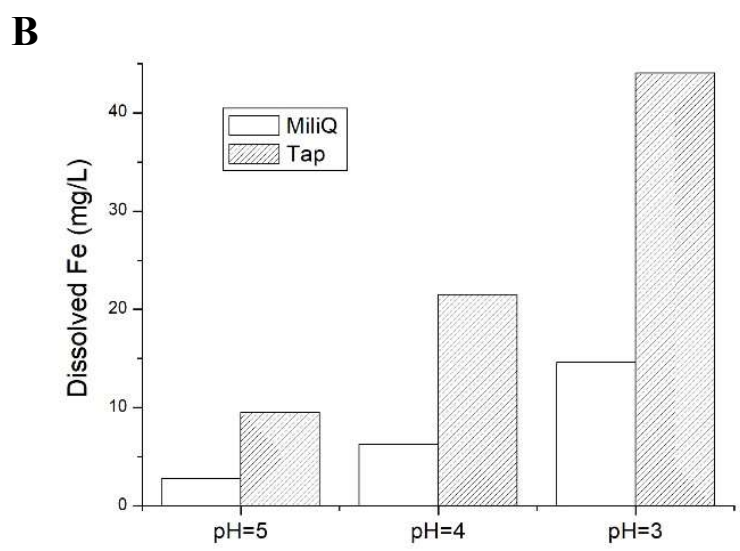

424

425 Figure 5: Pseudo-fist order kinetic constants for the reductive degradation of PCP using

426 Mili-Q and tap water at different $\mathrm{pH}$ values (A). Dissolved iron at the end of the 427 reductive process using Mili-Q and tap water at different $\mathrm{pH}$ values (B).

428 


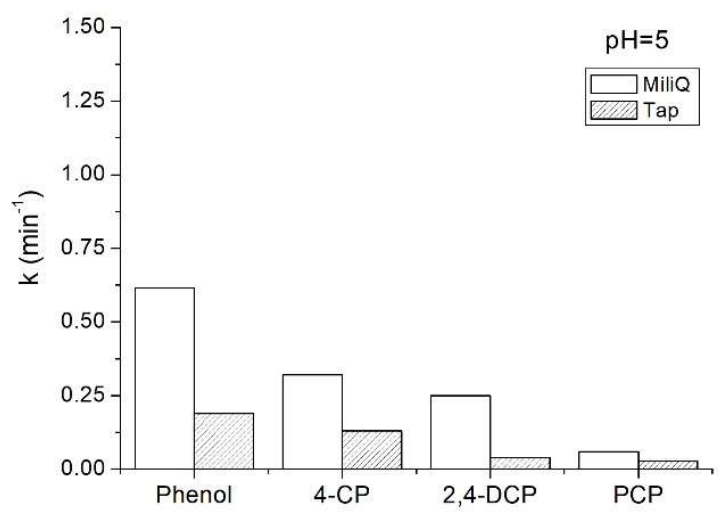

429

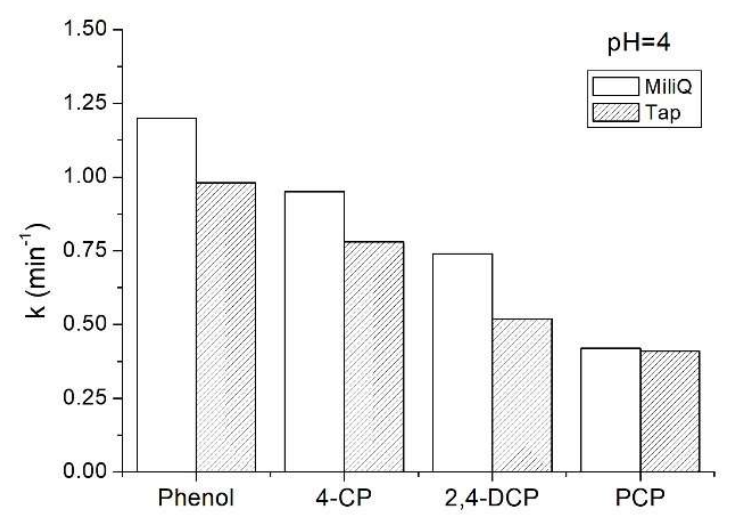

430

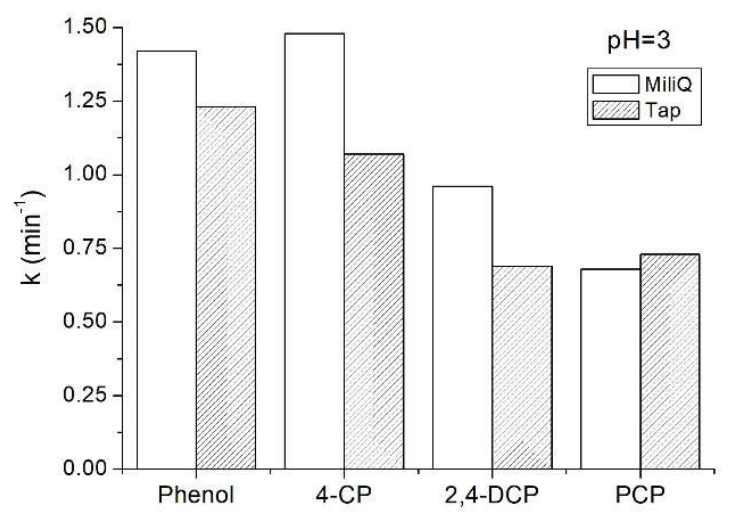

431

432 Figure 6: Pseudo-fist order kinetic constants degradation of different compounds

433 employing the photo-Fenton process at different initial $\mathrm{pH}$ values. Empty bars represent

434 Mili-Q water solutions while lined bars represent tap water solutions.

435

436 
437 Table 1: Tap water composition and main characteristics

\begin{tabular}{|l|r|l|r|}
\hline $\mathrm{pH}$ & 7.8 & $\mathrm{Cl}^{-}(\mathrm{mg} / \mathrm{L})$ & 26.8 \\
\hline Conductivity $(\mu \mathrm{S} / \mathrm{cm})$ & 493 & $\mathrm{NO}_{3}^{-}(\mathrm{mg} / \mathrm{L})$ & 2.63 \\
\hline $\mathrm{CaCO}_{3}(\mathrm{mg} / \mathrm{L})$ & 147 & $\mathrm{SO}_{4}^{2-}(\mathrm{mg} / \mathrm{L})$ & 28.1 \\
\hline Free Chlorine $(\mathrm{mg} / \mathrm{L})$ & 1.15 & $\mathrm{Na}^{+}(\mathrm{mg} / \mathrm{L})$ & 18.7 \\
\hline
\end{tabular}

438 